\title{
Nacionalismo ruso y régimen soviético
}

\author{
RaQuel Sanchez Garcia *
}

RESUMEN ABSTRACT

Más que una ideologia política concreta, el nacionalismo ha sido una

tendencia generaliza en el mundo político ruso. Sus relaciones con el poder han resultado siempre ambiguas. En los años de la autocracia zarista se alió con el imperialismo ruso, aunque siempre hubo un sector crítico entre algunos eslavófilos. Desde la instauración de la Unión Soviética, la ambigüedad del nacionalismo ruso con

el poder central se hizo aún más notoria, desde un inicial enfrentamiento hasta la alianza en la Segunda Guerra

Mundial. Con el fin de la URSS, el nacionalismo ruso ha mostrado de nuevo su oposición a las influencias del capitalismio y de occidente y ha aparecido como una opción política con una enorme fuerza en la actualidad.

PALABRAS CLAVE Antisemitismo, comunismo, eslavismo, extrema derecha, ideologias politicas, nacionalismo, Perestroika, Rusia, Unión Soviética.
Nationalism has been a general tendency in Russian politics. It has had ambiguous relationships with power. In zarist autocracy years, it formed an alliance with Russian imperialism, although there was a group of critics amongst the slavophiles. The ambiguity of Russian nationalism with the central power became more evident in soviet years: struggle in Revolution times and approach in Second World War. Since 1991, Russian nationalism has been against the capitalist and western influences in Russia. Nowadays, it is a political option that becomes stronger.

\section{KEY WORDS}

Antisemitism, comunism, extrem right, nationalism, Perestroika, political ideologies, Russia, slavism, Soviet Union.

* Facultad de Geografia e Historia, Universidad Complutense de Madrid. 
A lo largo de los años ochenta y noventa, la gran familia soviética estallaba de pronto en mil pedazos por conflictos internos de los que en occidente apenas teniamos noticia. En aquella confrontación era precisamente el hermano mayor, el pueblo ruso, el que parecía haber resultado más perjudicado por la destrucción de la gran falacia de la hermandad soviética. El desarrollo de movimientos nacionalistas por doquier también había llegado a Rusia, alcanzando en el seno de la antigua Unión una complejidad de tal calibre que condujo a la desestabilización de un estado que ya estaba bastante desarticulado como para necesitar más problemas.

Sin embargo, al acercarse al nacionalismo ruso, no hay que contemplarlo desde una perspectiva unitaria, pues su propia complejidad presenta un panorama de muy distintas formas de concebir la idea nacional: desde el nacionalismo radical (del que nos ocuparemos aquí) al nacionalismo democrático, que ha sido en toda la ex-Unión Soviética la principal forma de articulación política moderada. El movimiento «Rusia democrática», dirigido en un principio por Yuri Afanasiev, trató de representar este papel, aunque tuvo serios problemas organizativos hasta que se estructuró alrededor de Yeltsin y los parlamentarios demócratas en el Parlamento ruso.

El nacionalismo ha venido a llenar el vacío ideológico producido tras el final del sistema comunista y de los setenta años de aislamiento cultural e intelectual. La búsqueda de la patria y el renacimiento del sentimiento religioso son los dos mecanismos que definen la nueva identidad rusa. A pesar de esto, nacionalismo radical y comunismo no se han opuesto, pues muchos dirigentes comunistas (de todas las repúblicas de la antigua Unión Soviética) contemplando la degeneración del panorama político, no vieron otra salida que dar un viraje hacia el nacionalismo, identificando el capitalismo con lo extranjero. Estos «malabares políticos» se pusieron claramente de manifiesto de 1985 a 1990, período en el que el PCUS, sobre todo en Rusia, estuvo promoviendo una ortodoxia ideológica que en esta república defendió Poliaskov basándose en un marxismo-leninismo de carácter nacionalista y ortodoxo.

No podemos afirmar que el nacionalismo ruso tenga las mismas características que el nacionalismo radical de Europa occidental, las diferencias son importantes, aunque la esencia xenófoba parece ser la misma. En Rusia el enemigo no es el extranjero que acude a buscar trabajo, el enemigo es indefinido: el capitalismo, el estalinismo, los renovadores, las minorias, los judíos..., e incluso los masones, como decía Pamiat en su manifiesto (lo curioso es que en Rusia nunca ha habido masones). Se plasma en el sentimiento de frustración de quienes han sido una de las 
dos grandes potencias y ahora no son más que un pueblo en busca de su identidad. La llamada a los rusos de otras repúblicas forma parte de ese sentimiento de angustia, especialmente cuando se ven rechazados, de ahí que haya comenzado a generarse un pensamiento que se caracteriza por la autorreclusión y la exclusión de todo lo que se ha considerado, a lo largo del tiempo, como agresor de la esencia nacional. Pero el nacionalismo ruso no es un fenómeno nuevo, pues siempre ha existido en Rusia un sentimiento patriótico que en sus manifestaciones más exacerbadas ha derivado en prácticas xenófobas, agresivas $y$, cuando ha sido sostenido por el Estado, imperialistas.

Uno de los periodos más interesantes en la evolución del nacionalismo ruso son precisamente los años en que tuvo que convivir con el sistema comunista, años en los que contemplamos desde la simbiosis entre ambas ideologías (dando lugar a productos teóricos bastante peculiares) hasta la separación y diversificación de las mismas tras la muerte de Stalin. El interés de este periodo histórico viene dado por la relación determinante que se establece entre nacionalismo y poder político, relación que se ha conformado en toda la historia de Rusia como un juego de interdependencias y sutiles manejos, alianzas y justificaciones ideológicas, en las que el nacionalismo ha servido tanto para legitimar la expansión territorial como la oposición política.

\section{ANTECEDENTES}

Históricamente, la formación de la conciencia nacional rusa ha tenido dos artífices principales: Ia Iglesia Ortodoxa y el Estado. Este proceso de consolidación de la idea nacional panrusista comenzó en la Edad Media, período de expansión de los rusos, pero el mayor desarrollo de sus elementos teóricos fundamentales (los símbolos nacionales y religiosos) tuvo lugar en el siglo xix. Los vehículos de difusión de este programa políticoreligioso fueron muy variados, pero tal vez habría que destacar el papel de la literatura, medio fundamental de expresión en Rusia, tanto por la censura imperante como por tradición propia.

Hay dos hechos que tienen una importancia decisiva en la caracterización del nacionalismo ruso como ideología reacia a lo occidental: uno es el reinado de Pedro el Grande (considerado por algunos radicales ortodoxos como el Anticristo) y otro, la llamada "Gran Guerra Patriótica" contra Napoleón en 1812, que unió la lucha bélica a la lucha intelectual por el rechazo de la cultura europea, y dio paso a un cada vez mayor interés por la búsqueda de la esencia rusa. Pese a esto, la invasión napoleónica también 
supuso la reactivación del enfrentamiento entre los autócratas y los liberales, preocupados también por el lugar que debería ocupar Rusia en el mundo. Al igual que en otros paises, entre ellos España, en los grupos liberales rusos existía una especie de esquizofrenia ideológica acerca de lo que podia representar para la modernización del país la llegada no de los soldados napoleónicos, evidentemente, sino de los avances jurídicos y administrativos que Napoleón y sus legisladores portaban consigo. Por otro lado se encontraba el sentimiento nacional de defensa de las propias fronteras. Las manifestaciones de estas inquietudes intelectuales se plasmaron sobre todo en la literatura, durante la llamada "década maravillosa» (1838-1848), años en los que Pushkin, Lermontov y otros cantaron las alabanzas a la belleza de su tierra.

La primera formulación sistemática de un pensamiento nacionalista propio, el eslavismo, nace también en esta época como reacción a dos publicaciones sumamente críticas con la autocracia: la «Primera Carta Francesa», de P. Ya. Chaadayev, publicada en 1836 en el periódico Telescopio, y La Russie en 1839, del Marqués de Custine. Ambas obras coinciden muy directamente al considerar a Rusia como una prisión, cuyo futuro ha de pasar necesariamente por el contacto con occidente ${ }^{1}$.

El eslavismo tiene unas claras raíces culturales y literarias, pero políticamente se articuló en función de la «trinidad» del Conde Uvarov: Autocracia, Ortodoxia y Nacionalidad, tres elementos que han influido en gran manera en el nacionalismo del siglo $x \mid x$ y del siglo $x x$. La autocracia es presentada como la mejor forma de gobierno para Rusia, pues aporta la estabilidad que el país necesita, denostando las reformas, acusadas de contribuir a fomentar el desorden interno. El otro pilar de la estabilidad nacional es, evidentemente, la Iglesia. De esta forma, se constituye la nacionalidad rusa, y encuentran sentido las políticas de rusificación practicadas por la autocracia. La rusificación es un aspecto muy importante en la caracterización del nacionalismo ruso respecto de los nacionalismos de otros países europeos, pues la existencia de minorías étnicas determinaba en gran medida la estabilidad del Estado según la concepción imperante, ya que dichas minorias tenian una voluntad de aislamiento y unos comportamientos propios muy claros.

Pero sería un error identificar la política estatal con el eslavismo como movimiento intelectual, pues si bien los eslavófilos eran monárquicos y poco activos políticamente, se enfrentaban a la autocracia al considerar 
que la autoridad del zar procedía del pueblo, y no tenía, por tanto, origen divino.

Dentro de la primera generación de eslavófilos existieron distintas posturas respecto a la sociedad ideal, pero en general todos abogaban por una forma de vida tradicional y campesina, defendiendo la obshchina, la comuna rural, como principal propuesta y rechazando la mecanización, el individualismo y el racionalismo del mundo occidental. En definitiva, la sociedad rusa pasaba por ser una entidad regresiva, con valores tradicionales que Alexei Khomiakov (1804-1860) denominaba sobornost (su tradición viene a equivaler a estos dos conceptos comunidad-comunalismo).

El mundo occidental es contemplado como un sistema en decadencia, con inmensos problemas sociales a los que habia que oponer la tranquilidad (tan sólo aparente) del Imperio Ruso ${ }^{2}$. En este contexto, Rusia aparece como la fuerza del futuro, que ha seguido una distinta línea de desarrollo (idea elaborada por Ivan y Konstantin Aksakov), y que tiene una misión que desempeñar en los años venideros. Este mesianismo, que justificó el expansionismo por Asia, recogía antiguas tradiciones acerca de Moscú como la Tercera Roma.

Los llamados neoeslavófilos constituyen la segunda generación de este movimiento, que se caracterizó por la fusión del mesianismo con las ideas acerca de la superioridad de la raza eslava, conceptos que formarian la base del paneslavismo. El paneslavismo también conoció formas más y menos extremas de comprensión ${ }^{3}$. Los filósofos y pensadores rusos se apropiaron del término, en algunas ocasiones con la clara finalidad de justificar el expansionismo ruso; éste es el caso de Mikhail Petrovich Pogodin (1800-1875), quien en su Carta sobre la historia de Rusia al conde Stroganov (redactada en 1838 y publicada en 1867) retomaba la idea de la

\footnotetext{
La relación de lbs intelectuales rusos con occidente ha sido siempre muy controvertida, como ya se ha dicho. Para el caso de los eslavófilos, contamos con el interesante, aunque ya antiguo, libro de Nicholas V. Riasanovsky, Russia and the West in the Teaching of the Slavophiles. A Study of Romantic ldeology. Gloucester, Mass., Peter Smith 196; más reciente: VV.AA., Russia and the ldea of Europe: A Study in Identity and International Relations, Londres, 1996. Para profundizar en estas cuestiones: Hans KOHN, Paneslavism. Its History and Ideology, Indiana University Notre Dame Press, 1953, M.B. PETROVICH, The Emergence of Russian Paneslavism, 1856-1870, Greenwood Press Publishers Westport 1956, 1984 y A. WALICK!. The Slavophile Controversy. History of a Conservative Utopia in Nineteenth-century Russia Thought, Clarendon Press Oxford 1975.

La palabra "paneslavismo" apareció por primera vez en 1826 en los textos del escritor eslovaco Jan Herkel; posteriormente seria elaborada ideológicamente como una forma moderada de defensa de los derechos y libertades de los checos y otros eslavos en el imperio Austrohúngaro por pensadores como F. Palacky, Kollar, Shafarick, etc.
} 
unidad eslava: «... Unamos a esta multitud de más de treinta millones de nuestros hermanos y primos, los eslavos, que están diseminados por el conjunto de Europa...” ${ }^{4}$.

Hay por último dos pensadores fundamentales en la configuración del eslavismo como un movimiento precursor y polivalente: N. Ya. Danilievsky y F. Dostoievsky.

El pensamiento de Danilievsky (1825-1885) tiene unas implicaciones políticas determinantes; su influencia será muy importante en el siglo xx, ya que fue capaz de reunir todas las ideas y elementos de juicio acerca del declive del mundo occidental y de ofrecer una argumentación coherente en favor de la civilización oriental, fundada en la filosofía griega, la Iglesia Ortodoxa y la autocracia. De esta forma, Rusia, nación histórica, aparece como un modelo para los demás pueblos eslavos, ya que ha reunido en si misma las cuatro grandes creaciones de la civilización: el monoteísmo hebreo, la filosofía del mundo y del arte griegos, la idea romana del estado y el desarrollo económico occidental ${ }^{5}$. La filosofía de Danilievsky fue un buen arma para los paneslavistas frente al cada vez más fuerte pangermanismo.

En Dostoievsky (1821-1881) también encontramos alusiones a la misión histórica de Rusia, que es presentada como la luz del este ${ }^{6}$, aunque sus preocupaciones están más próximas al mundo de las aspiraciones morales y de las utopias ${ }^{7}$. En sus planteamientos éticos hay una contraposición de comportamientos morales en función de la nacionalidad que viene a ser una crítica al mundo occidental, inmerso en el materialismo, y alejado de la espiritualidad rusa ${ }^{8}$. Las ideas de Dostoievsky han tenido gran influencia en la literatura posterior, especialmente en Solzhenitsyn.

Los años previos a la Revolución se caracterizaron políticamente por una progresiva radicalización de los conservadores (en 1905 se formó del Partido Monárquico) y por una ideología nacionalista de preservación basada en los postulados de Pobedonotsev y de Uvarov. La Unión del Pueblo Ruso mantuvo unos planteamientos aún más extremos acerca de la pureza de la raza, el antisemitismo, la violencia y el dominio ruso.

Hans KOHN, op. cit., p. 115.

Danilievskr, Rossiya i Yevropa, St. Petersburgo, 1869 (Rusia y Europa. Investigación acerca de las relaciones culturales y politicas entre los mundos eslavo y germano-latino).

Sobre todo en El idiota, 1867.

Ver, por ejemplo, Notas invernales sobre impresiones veraniegas, 1862

Tal vez el mejor exponente sea El jugador, 1866 


\section{EL NACIONALISMO RUSO DURANTE EL RÉGIMEN SOVIÉTICO}

Con el triunfo de la revolución en Rusia nacía necesariamente el problema de articular un gran territorio en función de los intereses del proletariado, sobre todo tras el fracaso de la expansión revolucionaria por Europa en los años veinte, momento en el que se define el "socialismo en un solo país". De esta forma el programa bolchevique, que partía de la aproximación (sblizhenie) y se dirigía a la fusión del proletariado de distintas naciones (sliyanie), se reestructuró hacia la creación del pueblo soviético (sovietskii narod). La Revolución parecía una nueva oportunidad para poner a Rusia en contacto con occidente, pero el ya citado fracaso de la expansión revolucionaria trajo consigo el rechazo a occidente y el resurgimiento de un mesianismo, esta vez comunista, que tenía mucho que ver con el nacionalismo, y que dio lugar a una ideología propia, promovida desde el nuevo Estado, bautizada por los marxistas alemanes como nacional-bolchevismo.

El nacional-bolchevismo supuso un compromiso de las ideas revolucionarias con el poder, compromiso en el que entraban a formar parte elementos tradicionales como eran la reverencia al jefe (al zar), en este caso a Lenin, y la identificación de Moscú con la Tercera Roma, cuyo vehículo de difusión iba a ser la III Internacional. Agursky lo definió de la siguiente forma: "The Russian statist ideology that legitimises the Soviet political system from the Russian étatite point of view, contrary to its exclusive Marxist legacy... National-Bolshevism does not reject Communist ideology though it strives to minimise its importance to the level necesary for legitimacy... National-Bolshevism in its original form strove for world domination, conceived as the universal Russian Empire cemented by Communist ideology.... ${ }^{9}$. Gran parte de este compromiso entre ideología revolucionaria y estado vino enunciado ya por Lenin en algunas de sus obras, en las que hablaba de la necesidad urgente de atención que tenían las condiciones internas del país y de la creación, por consiguiente, de un partido nacional de la izquierda ${ }^{10}$. Este hecho iba a tener una trascendencia fundamental en la justificación teórica de Stalin, pues era una forma de encontrar precedentes para la configuración del socialismo en un solo país como doctrina política. Pese a todo, pueden entenderse las intenciones de Lenin en el contexto en que se desarrolló su actividad política, y sobre todo,

\footnotetext{
9 M. AguRSky, The Third Rome: National-Bolshevism in the USSA, Boulder, Col Westview Press, 1987, p. XV.

10 LENIN, “izquierdismo: entermedad infantil del comunismo 1920", en Obras completas, vol. XXXIII, Akal, Madrid, 1974.
} 
teniendo en cuenta las dificultades de organización que presentaba la sociedad rusa, necesitada de un proyecto común que estuviera fundamentado en el resurgir de Rusia como nación.

La postura de los nacionalistas tradicionales fue muy diversa: unos emigraron, otros desaparecieron y algunos encontraron en la defensa de la nueva patria soviética el objetivo de su pensamiento. Entre estos últimos destacan Nikolai Ustryalov y Boris Pylniak. Ambos veían la nueva situación como el ansiado resurgir de Rusia frente a un Occidente en decadencia ${ }^{11}$. La colección de artículos de estos autores se llamó Smena Vekh (Cambio de siglo), recoge el fundamento de sus ideas, y también, en parte, la frustración de las mismas, ideas que, por otro lado, tuvieron una gran repercusión entre los emigrados.

El nacional-bolchevismo quedó asegurado con la llegada de Stalin al poder, especialmente con la destrucción de la tradicional cultura campesina por la industrialización acelerada y los planes quinquenales. Este hecho dio paso a una reacción contra el sistema soviético que fundamentaría toda una línea de pensamiento nacionalista regresivo y tradicional, que se mantuvo latente hasta la muerte de Stalin, cuando produciría sus primeros frutos, sobre todo en el campo literario. Stalin sería el creador de la organización federal soviética, cuestión ésta en la que ya había trabajado desde sus primeros artículos en 1904 y 1913. Su teoría presenta una definición sociohistórica de la nación: "La nación es una comunidad estable, históricamente constituida, de lengua, de territorio, de vida económica $y$ de formación psíquica, que se traduce en una comunidad de cultura".

Esta definición recoge una gran parte de los planteamientos del marxista austríaco $O$. Bauer, sin hacer referencia a la comunidad de destino. Concibe Stalin la nación como un conglomerado de elementos que alcanza su máxima expresión en el capitalismo industrial: "La nación es una categoría histórica, y es una categoría histórica de una época determinada, la del capitalismo ascendente" ${ }^{12}$.

Partiendo de un análisis que reconoce la existencia del derecho a la autodeterminación de las naciones, Stalin aplica sus conceptos a las realidades existentes, negando que ninguno de los elementos que constituyen la nación sea el principio fundamental para resolver la cuestión nacional. La clave está pues en la "unión internacional de los obreros»: "La idea de la autonomía nacional sienta las premisas psicológicas para la división del

N. Ustryalov, Pod znakom revolyutsii, (Bajo la ley de la revolución, 1927).

STALIN, El marxismo y la cuestión nacional, Ed. Fundamentos, Madrid, 1976, p. 31 
partido obrero unido en diversos partidos organizados por nacionalidades. Tras los partidos se fraccionan los sindicatos, y el resultado es el completo aislamiento. $Y$ así, un movimiento de clase unido se desparrama en distintos riachuelos nacionales aislados ${ }^{13}$. Siguiendo estos planteamientos, rechaza la idea nacional por ser expresión de los intereses de clase, y funda en ellos su práctica política de desplazamiento de nacionalidades y etnias de unas repúblicas a otras. Entraban aqui en juego las políticas de rusificación, de las que hemos hablado anteriormente, y que han sido practicadas a lo largo de la historia rusa en función de distintas interpretaciones políticas.

Ya en la constitución de 1918 se decidió organizar el territorio bajo forma federal. A comienzos de la década de los veinte, Stalin, Kamenev y Manuilski discutían acerca de la posibilidad de articular el territorio según un esquema que mantuviera una federación rusa dominante y unas repúblicas autónomas de nacionalidad no rusa. Durante 1923 se desarrollaron estas propuestas a través del fomento de la lengua nacional y de la korinezatsiya, es decir, el nombramiento de personal nativo en los altos cargos locales con preferencia sobre los rusos o los rusificados.

El proceso de rusificación comenzó en los años treinta con el impulso a la lengua rusa en las escuelas de la URSS ${ }^{14}$, traslados de población, etc., y respondía al intento de Stalin de crear el pueblo soviético. El predominio ideológico de los rusos tuvo su máxima expresión en la Segunda Guerra Mundial, cuando fueron identificados con la URSS como "el hermano mayor»; al final de la Guerra, Stalin hablaba de Rusia como la guía de la URSS que salvó al resto de las repúblicas del nazismo.

Stalin fomentó el nacionalismo ruso durante la Segunda Guerra Mundial, mezclando los viejos símbolos con los nuevos: en un gran mitin en la Plaza Roja el 7 de noviembre de 1941 Stalin hizo referencias tan dispares como aludir a la valentía del Ejército Rojo, y a los antepasados gloriosos como Nevski o M. Kutuzov, que es considerado el salvador de Rusia frente a Napoleón. De la misma forma, Stalin se identificaba con Iván IV o rehabilitaba a la Iglesia Ortodoxa (1941), utilizando para sus alocuciones el tradicional saludo de los patriarcas: "Hermanos y hermanas, compañeros (camaradas) campesinos...".

El fin del enfrentamiento mundial y el preludio de la guerra fría hacian necesaria una vuelta al marxismo ortodoxo frente al capitalismo, por lo que los elementos nacionalistas fueron un tanto desplazados: en Kazajstán,

13 Ibidem, p. 61.

14 Se dieron casos de auténtica desvirtuación de la lengua nacional, como sucedió en Moldavia, donde se impuso la obligación de utilizar el alfabeto cirílico en el idioma nativo. 
Kirguizistán, Azerbaiyán y dos repúblicas de la RSFSR (Yakutia y Daguestán) los nacional-comunistas fueron expulsados del Partido. Esto no quiere decir que la idea del patriotismo quedara abandonada, de hecho la prensa se dedicó en 1949 a criticar el "antipatriótico teatro crítico", pero ahora comenzó a manifestarse en ataques a los enemigos infiltrados, que eran los judíos (o los cosmopolitas, como irónicamente los llamaba Stalin). Revivía un elemento que siempre ha existido en la sociedad rusa: el antisemitismo. Dos miembros del Comité Judío Antifascista, Lozovsky y Mikhoels, fueron asesinados. Stalin murió obsesionado con conspiraciones de judíos agentes del capitalismo.

Directamente relacionado con la Guerra y la situación política interna apareció en 1947 el libro de Berdiaev La idea rusa, que recogía con un nuevo barniz la defensa del expansionismo ruso en un sentido tradicional, con las consabidas alusiones al mesianismo, al espíritu nacional y demás lugares comunes.

En época de Khruschov, el nacionalismo quedó atemperado por las esperanzas de revisionismo y por el desplazamiento de la atención a las reformas económicas y administrativas. Frente al posible reformismo, y como reacción al XX Congreso del Partido en 1956, nació un nacionalismo neo-estalinista que era en realidad una versión rusa del fascismo. Los principales integrantes de este grupo eran Fetisov, M. Antonov, V. Bykov y O. Simirnov, a quienes se les encerró en psiquiátricos entre marzo y abril de 1968. Por supuesto, se oponían al reformismo de Khruschov, pero posteriormente tampoco aceptaron a Brezhnez al considerarlo demasiado débil. Estuvieron vinculados al periódico samizdat Slovo natsii (La palabra de la nación), que acusaba a los políticos liberales de ser los culpables de la destrucción de la vitalidad y de la pureza de la raza rusa. Abogaban por una Rusia unida bajo la égida de la Iglesia Ortodoxa. Para Fetisov, los judios han sido los responsables del caos de la civilización y dada esta situación, afirmaba este neoestalinista, los regímenes de Stalin y Hitler no sólo han sido deseables, sino históricamente inevitables. La restauración de la sociedad campesina y tradicional en la Rusia europea era su objetivo, además de la transferencia de la industria a Siberia. Las relaciones de este grupo, cuyas ideas han encontrado eco en el ultra Shimanov, con los estalinistas han sido muy ambiguas.

En los últimos años del gobierno de Khruschov y en la época de Brezhnev comenzó a desarrollarse en Rusia un nacionalismo al margen de la ideología oficial ${ }^{15}$ (lo que no impidió que si no conexiones directas, sí

En el lado oficial se contaba con Mikhail Suslov, consejero de Brezhnev, como ideólogo de un nacionalismo de preservación que consistía sobre todo en acerbas criticas a los disidentes. 
hubiera tolerancia para algunos movimientos y personajes). También para la oposición liberal esta etapa fue definitiva, pues la invasión de Checoslovaquia en 1968 acabó con todas las esperanzas de democratización en Rusia.

En suma, podemos detectar en estos años de transición la definición de dos corrientes principales del nacionalismo ruso; por un lado estarían los que se denominan vozrohdenets, eslavófilos y nacionalistas religiosos de talante liberal y anticomunista (de los que se consideran herederos muchos políticos actuales); por otro, los nacionalistas gran-rusos, cercanos al fascismo, antisemitas y autoritarios, que mantenían contactos con los estalinistas.

El nacionalismo ruso tuvo en la época de Brezhnev dos formas principales de manifestación: en la literatura y en la política, disfrazada de estudio de la tradición rusa. La literatura ha sido en Rusia, como en tantos otros países, una de las principales maneras de oponerse al sistema. Los llamados derevenshchiki, escritores aldeanos o campesinos, recibieron este nombre no tanto por su procedencia como por los temas de sus obras, que se situaban al margen del realismo socialista, analizando el impacto de la transformación del campo ruso a consecuencia de la industrialización y de la colectivización.

Aunque actualmente muchos continúan escribiendo, se dieron a conocer antes. En la década de los cincuenta, los nombres más conocidos eran los de S. Zalygin, V. Tendriakov ${ }^{16}$ y G. Troepolsky; en los sesenta alcanzaron gran difusión V. Belov ${ }^{17}, F$. Abramov ${ }^{18}, V$. Astafev, V. Likhonosov, B. Moshaev, E. Nosov, V. Solunkhin, y V. Shukshin. De los setenta a la actualidad destaca especialmente Rasputin ${ }^{19}$, cuyos testimonios han tenido también proyección política por su preocupación ecológica. Rasputin

i6 V. Tenoriakov, Rroizvidienia, (Obras), Eds. Pravda, Moscú, 1991; Liudi ili neliudi, (Personas o no personas), Sovremennik, Moscú, 1990.

17 V. I. Belov, Rasskazy i povesti, (Relatos y novelas), Sovremennik, Moscú, 1987; Vsio vperedi: roman, (Todo por delante), Sov. pisatel', Moscú, 1987.

18 F. A. Abramov, Brat'ia i siostry: roman, (Hermanos y hermanas: novela), Sov. Rossiya, Moscú 1987; Dela rossiiskie: povesti i rasskazy, (Asuntos rusos: novelas y relatos), Molodaia guardiia, Moscú, 1987; Vokrug da okolo, (Alrededor de aqui), Posev, Frankfurt-Main, 197-?; Iz kolena Avvakumova. Povesti, razzkazy, (De la rodilla de Abakum), Sovremennik, Moscú, 1989; Sobranie sochineii, (Obras completas), Judozhestvennaia literatura, 1983 v. 1.

19 V. G. Rasputin: Poslednii srok; Proshchanie s Matioroi, Pozhar: povesti, (El último plazo; Adiós a Matiora; Pozhar: novela), Sov. Rossiia, Moscú, 1986; Izbrannye proizvedeniia v dvuj tomaj, (Obras escogidas en dos tomos). Judozhestvennaia literatura, Moscú, 1990; Chto v slove, chto za slovom?, (¿Qué hay en las palabras, qué hay detrás de las palabras?) Vost. Sib. Irkust, 1987; El adiós a Matiora, Círculo de Lectores, Barcelona, 1990. 
afirmaba seguir la tradición literaria rusa de la preocupación por los valores eternos (en la línea de Dostoievsky), y siempre se ha mostrado muy pesimista respecto a la regeneración de la sociedad rusa, esquilmada por la modernización y la influencia occidental ${ }^{20}$.

Los temas de los derevenshchiki se mueven en la reivindicación de una vida campesina y de unos valores morales (los de la Iglesia Ortodoxa) que rezuman tradicionalismo en aspectos como son los relativos a la situación de la mujer.

La ideología del nacionalismo ruso se articuló en los años sesenta en función de unos principios básicos con variantes particulares según los pensadores o movimientos políticos. La desilusión hacia el comunismo era uno de estos fundamentos, que llevó a contemplar con agrado la democracia occidental, pero a preferir, en el caso de los radicales, una solución autoritaria que restableciera los valores morales tradicionales y la influencia de la Iglesia.

Con respecto al antisemitismo, no es posible olvidar la influencia que ha tenido el antiguo panfleto Los Protocolos de los Ancianos de Sión. Este texto, fuente teórica de todo el pensamiento xenófobo ruso, se basó a su vez en la obra de Hermann Goedsche que llevaba por nombre Biarritz, publicado en Berlín entre 1868 y 1870 . W. Laqueur ha estudiado los Protocolos con detenimiento en su obra Russia and Germany y ha llegado a la conclusión de que se pueden incluir dentro de la tradición conservadora rusa por afirmaciones como que todas las revoluciones son obra de conspiradores que no buscan más que el caos y la anarquia. Por otra parte, los Protocolos enlazan con las líneas del pensamiento antisemita europeo, especialmente el alemán, por cuanto hablan de la existencia de un grupo de instigadores de desórdenes, que serían los judíos, y cuyo único objetivo estaría en destruir la sociedad tradicional. Junto a los judíos, los Protocolos contienen fuertes acusaciones a los masones y librepensadores como colaboradores de los judíos. Los Protocolos, pese al excéntrico panorama que presentan, han tenido una gran influencia, como se ha dicho más arriba, tanto en los rusos blancos emigrados (quienes entendieron la Revolución como una conspiración de judios) como en grupos radicales contemporáneos ${ }^{21}$. El antisionismo, máscara de un auténtico antisemitismo,

\footnotetext{
${ }^{20}$ Especialmente destacable en El adiós a Matiora, obra en la que también entra en juego el fracaso del comunismo para la regeneración nacional.

21 Pamiat (Memoria) ha basado su manifiesto, aparecido en 1987, en los Protocolos, especialmente por la influencia del fotógrafo Vasiliev, quien ha hecho resurgir estos principios con claras intenciones demagógicas. El libro de Norman COHN, El mito de la conspiración judia mundial.
} 
es la clave que hizo conectar el nacionalismo radical con las altas esferas del Partido, sobre todo tras la Guerra de los Seis Dias en 1967. Si no fuera así, no se explicaría la publicación totalmente libre de obras como la de T. Kichko ${ }^{22}$ con ilustraciones del periódico alemán nazi Der Stürmer. Lo mismo cabe decir de Peligro, sionismo, de $\mathrm{Y}$. Ivanov, impreso en los setenta.

La idea de Rusia como víctima es uno de los elementos teóricos principales que aporta el pensamiento nacionalista de los sesenta y setenta. Para estos autores, Rusia aparecía como la víctima de todo el proceso revolucionario, y especialmente, durante el estalinismo, pues en aras de la construcción del pueblo soviético, el pueblo ruso perdió su identidad y su cultura. Los desplazamientos de población, el abuso de los recursos propios y la abolición por Stalin del Partido Comunista de la RSFSR (1925) han sido los argumentos básicos que han ofrecido los nacionalistas. En algunos casos se ha acusado a Lenin de ser un antipatriota y de odiar a Rusia ${ }^{23}$. Ante el desencanto, la mayoría de los opositores volvieron sus ojos a las tradiciones prerrevolucionarias idealizando al papel político de la duma, el paneslavismo o estudiando el siglo XIX en la búsqueda de los elementos de la identidad nacional rusa destruida por Stalin.

No podemos olvidar aquí la ya citada obra de Berdiaev La idea rusa, que ha tenido una gran influencia en el surgimiento de movimientos como la Unión Social Cristiana Rusa para la Liberación del Pueblo (VSKhSON, fundada en 1964 por Igor Ogurtsov, que contaba con E. Vadim como ideólogo y M. Sado como organizador). La VSKhSON afirmaba que el comunismo habia desfavorecido los intereses nacionales de Rusia, destruyendo su esencia. Planteaba una vuelta a los valores socialcristianos de la familia y de la propiedad privada, una sociedad regida por un Consejo Supremo y una Asamblea Popular elegidos por el pueblo. Hablaban en sus escritos de la Gran Rusia y de la existencia de una hermandad entre las naciones eslavas. Los miembros de esta organización fueron arrestados en 1967.

En la línea de la reinterpretación histórica buscando asideros ideológi$\cos$, se ha movido toda una corriente intelectual que actualmente ha dado

\footnotetext{
Alianza Editorial, Madrid, 1983, analiza desde una perspectiva histórica el éxito de los Protocolos en Rusia. Para estudiar el mismo fenómeno en la época contemporánea, puede leerse el libro de W. LAQUEUR, La centuria negra. Los origenes y el retorno de la extrema derecha rusa, AnayaMuchnik, Madrid, 1995.

${ }_{22}$ T. KichKo, lyudaizm bez prikas (El judaismo sin adornos), publicado por la Academia de Ciencias, Moscú, 1964

23. A. SOlzHENitSYn en Lenin en Zurich, 1975.
} 
lugar sus más importantes frutos, pero que comenzó en la década de los sesenta, tras el desvelamiento oficial de los crimenes de Stalin. El más famoso historiador es el medievalista Likhachov, quien fue nombrado director de la Fundación para la Cultura Soviética y que comenzó a publicar en 1988 Nashe Nasledie (Nuestra Herencia) en un intento de rescatar la cultura pasada. Entre sus mayores empeños ha estado la idea de recuperar el pensamiento del filósofo religioso Florinski.

La moda del eslavismo en los años sesenta y setenta dio lugar a la formación de asociaciones como Rodina, constituida por grupos de estudiantes moscovitas que se reunieron en 1964 buscando la esencia eslava del pueblo ruso. Otra sociedad de este tipo, pero con más influencia, es VOOPIK: Sociedad Rusa para la Protección de Monumentos Históricos y Culturales. Gracias a su carácter cultural, fue aceptada por el régimen. Esta aparentemente inofensiva sociedad ha contado con individuos tan poco recomendables como Yemelyanov, fanático en todas sus manifestaciones (tanto en la defensa de la causa palestina como en su antisemitismo), que mató a su mujer y ha estado en un psiquiátrico.

Otra vertiente de la oposición nacionalista fue la periodística, donde se encontraban las publicaciones samizdat como Veche. Veche es el nombre de una antigua asamblea comunal existente en Novgorod. El periódico, del mismo nombre, fue publicado entre 1971 y 1974 bajo la estrecha vigilancia de la KGB. Osipov ha sido el director de Veche y representa uno de los tantos ejemplos de entusiastas leninistas, miembros del Konsomol que perdieron el norte tras las revelaciones de los crímenes de Stalin en la época de Khruschov. Osipov buscó alternativas en los primeros años del sovietismo, en Yugoslavia y en las ideas de los Trabajadores de la Oposición. Fue durante los dos años que estuvo en un campo de trabajo (196264) cuando se decantó hacia el nacionalismo estudiando el declinar moral del pueblo ruso, tema que desarrolló en distintos artículos en Veche. Osipov afirmaba que la sovietización ha sido el gran peligro para la cultura rusa, la gran víctima del estalinismo. Posteriormente, ha seguido manteniendo un claro rechazo a las reformas democráticas que, según él, están llevando a la anarquía social. Sus grandes enfrentamientos periodísticos con Yakovlev, el asesor de Gorbachov, fueron centro de atención durante meses en Rusia. Veche ha tenido colaboradores como A. M. Ivanov, gran amigo de Osipov, autor del manifiesto racista Slovo natsii.

Molodaya Guardia (Joven Guardia) fue el órgano de prensa del Konsomol y desde finales de 1967-68 comenzó a publicar artículos muy relacionados con el tema que aquí nos ocupa. La revisión de la historia rusa fue el centro de atención de estos artículos, entre los que destaca el 
publicado en abril de 1968: "Inevitabilidad", cuyo autor fue Chamaev, quien consideraba la historia rusa como un conjunto de sucesos y revoluciones en la que Lenin hace el mismo papel que los demás consolidadores del Estado, aunque a pesar de los errores y traiciones cometidos, siempre ha quedado la esencia de la patria rusa. Estos planteamientos fueron criticados por Yakovlev y el marxista Dementev. Las ideas de Chamaev han sido recogidas por nacionalistas actuales y han tenido cierto éxito popular.

En la misma línea que Molodaya Guardia, con mayor o menor tendencia a la derecha, han nacido otros periódicos como Nash Sovremennik (Nuestro contemporáneo) y Moskva (Moscú), ambos de la Unión de Escritores de la RSFSR.

Shimanov es un ultra extremista que comenzó a darse a conocer en el Moscú de la década de los setenta. Bebió directamente del pensamiento de Fetisov, el fascista neo-estalinista. Shimanov es un exaltado que detesta el Movimiento de Derechos Humanos, la democracia y la economía de mercado. Realizó un curioso análisis del paradójico papel que, según él, ha realizado el PCUS en la historia de Rusia. El Partido Comunista, afirma Shimanov, ha logrado apartar a Rusia del capitalismo y la comercialización, pero, por otro lado, debe abandonar el marxismo-leninismo para unirse a las masas a través de la Iglesia Ortodoxa. La esencia del pueblo ruso está en la ortodoxia religiosa, no en el marxismo-leninismo, y ha salido revitalizada tras los sufrimientos del período estalinista. Reclama también Shimanov el mantenimiento del imperio soviético para que Rusia pueda desempeñar su misión en el mundo.

Alexander Solzhenitsyn ha sido uno de los pensadores disidentes más influyentes y famosos. Sus planteamientos recogieron gran parte de la herencia tradicional, por lo que fue un punto de referencia de primer orden para los oponentes al sistema comunista que actuaban en el interior, aunque algunos de sus postulados hayan sido simplificados en exceso. Solzhenitsyn sostuvo desde siempre una clara vinculación con el nacionalismo basado en la filosofía de los estudiosos y pensadores tradicionales, con el consabido rechazo a todo lo que supone to occidental, a pesar de que vivió gran parte de su vida fuera de Rusia, inmerso en la cultura occidental. Su crítica continuó la tendencia rusa a utilizar la literatura como forma de expresión política ${ }^{24}$.

24 Para profundizar en Solzhenitsyn desde estas perspectivas, disponemos de abundante bibliografía, entre la que destacaria el libro de S.K. CARTER, The Politics of Solzhenitsyn, MacMillan, Londres, 1977, y en nuestro idioma la memoria de licenciatura inédita de José M. ${ }^{a}$ Faraldo que lleva por titulo Alexander Solzhenitsyn. 
Solzhenitsyn ha realizado un profundo análisis del estalinismo, cuyos fundamentos teóricos y pragmáticos sitúa en Lenin, quien representa el modelo de pensador dogmático que trataba de implantar sus ideales al margen de la cultura, creencias y formas de vida existentes en la sociedad rusa. De ahí que para Solzhenitsyn, Lenin no sea más que un antipatriota que dio el paso a las desvirtuaciones de la esencia nacional llevadas cabo en tiempos de Stalin ${ }^{25}$. Esta disolución de los principios morales y de la dignidad humana alcanza su máxima expresión en la existencia de los campos de prisioneros en el periodo estalinista ${ }^{26}$. Las propuestas de Solzhenitsyn pasan por las soluciones clásicas, del mismo cariz que las de Dostoievsky, es decir, abandonando todo recurso a la violencia, abogando por una resistencia pasiva ${ }^{27}$, y por una regeneración moral que llegaría tras la caída del comunismo, y que estaría fundada en los principios éticos de la tradición ortodoxa. En este esquema no cabría adoptar la democracia como forma de gobierno, pues la democracia en Rusia no provocaría más que desórdenes, como sucedió, afirma nuestro autor, en los meses que fueron desde febrero a octubre de 1917.

En 1973, Solzhenitsyn publicó su Carta a los dirigentes rusos en la que proponía los principios anteriormente mencionados como base de una regeneración que debería llevarse a cabo desde el Estado. Para ello sería necesario que éste, el Estado soviético, abandonase sus compromisos con el mundo comunista, preocupándose más por los problemas internos y por una posible guerra con China. De esta forma, se observa que Solzhenitsyn, como otros tantos nacionalistas tradicionales, admiraba la estructura del Estado soviético como forma de gobierno que había llevado a Rusia a ser una superpotencia. Así, afirmaba en 1973, que la legitimación del Partido no había de estar basada en el marxismo-leninismo, pues podía hallar en la tradición su más válido fundamento.

\section{LA IDEOLOGIA DEL NACIONALISMO RUSO EN LA ÉPOCA DE GORBACHOV (1985-1991)}

Los nacionalistas rusos del periodo que nos ocupa pueden ser clasificados en dos grupos: los demócratas y los conservadores (que W. La-

Esto es especialmente notable en Lenin en Zurich, 1975.

25 La mejor radiografía de esta situación es Archipiélago Gulag (1963-1968), que refleja la vida en los campos desde 1918 a 1956.

27 Un día en la vida de Iván Denisovich, 1959. 
queur denomina liberal-nacionalistas ${ }^{28}$ ). Los primeros, seguidores de la línea de Sajarov, han abogado por el multipartidismo y la democracia. Los segundos, centro de nuestro estudio, han apostado por un régimen autoritario por temor a la balcanización del antiguo imperio soviético. Analizaremos en este apartado los elementos definitorios del fenómeno que estamos estudiando para tratar de caracterizarlo y profundizar en el próximo punto en su capacidad política y sus cambios de estrategia desde la llegada de Gorbachov al poder y los acontecimientos que han sucedido a este hecho.

Como se ha podido ver en las páginas anteriores, existen en los textos y manifestaciones de los nacionalistas radicales una serie de temas recurrentes cuyo tratamiento se ha ido modificando según las circunstancias. La glasnost ha facilitado la difusión de los periódicos y las opiniones de los opositores al régimen, por lo que es más fácil conocer sus planteamientos, que se han centrado en las críticas a los políticos reformistas -acusados de la degeneración social-y en la apelación a las masas por medio de grandes concentraciones ahora permitidas. Estos temas recurrentes pueden esquematizarse en cinco aspectos:

- Rusia como víctima.

- Xenofobia (antisemitismo).

- Reinterpretación de la historia.

- Propuestas políticas: autoritarismo.

- Retorno a la Iglesia.

Rusia como víctima: La consideración de Rusia como víctima tiene dos vertientes: una culpa al capitalismo, y la otra al socialismo. La amenaza de occidente se manifiesta en el capitalismo, que según los nacionalistas trata de desvirtuar la esencia rusa con el dinero y su cultura católico-protestante. En este sentido han ido las críticas hacia el equipo reformista de Gorbachov, sobre todo hacia Yakovlev y Gaidar. Estas críticas alcanzaron su punto máximo con motivo de la Guerra del Golfo. El 27 de febrero de 1988 Pavel Gutiontov publicó en Izvestya un artículo titulado "Podmena" (Cambios) en el que analizaba el manifiesto de Pamiat. Gutiontov recordaba que el recurso a la amenaza exterior es el mismo argumento utilizado por Stalin para justificar las purgas de 1937-38.

28 W. LAOUEUR, "El retorno del nacionalismo ruso", en Politica exterior, invierno de 1993, vol. VII, n. ${ }^{\circ} 31$, pp. 49-61. 
Los nacionalistas acusan al régimen soviético de haber destruido la identidad rusa, tanto en sus símbolos como en sus aspectos materiales. Los desplazamientos de población y de recursos son los argumentos principales presentados por los radicales, junto al hecho de que Stalin aboliera, en 1925, el Partido Comunista de la RSFSR (del mismo modo que no han tenido periódico republicano propio). Incluso se ha llegado a decir que Lenin odiaba a Rusia. Algunos nacionalistas propusieron al final de la década de los ochenta la salida de Rusia de la URSS.

La definición de la identidad nacional rusa, problema de primer orden en la actualidad según ha dicho H.Carrère d'Encausse ${ }^{29}$, tiene connotaciones distintas respecto a otras repúblicas de la antigua URSS, pues en Rusia esta búsqueda muestra un carácter regresivo al mirar hacia la Rusia imperial ya desaparecida. Algunos autores han calificado esta identidad pretendida como desintegradora ${ }^{30}$.

Xenofobia (antisemitismo): Sobre este aspecto no insistiremos pues ya hemos hablado anteriormente de él; sólo cabe decir que con la apertura al exterior las iras de los nacionalistas se dirigen ahora también hacia los extranjeros occidentales que representan el espíritu del capitalismo. Por otra parte, en el repaso a la historia soviética algunos nacionalistas han creído encontrar más argumentos para la xenofobia al descubrir que varios revolucionarios de 1917 no eran rusos, si no lituanos, georgianos etc., y que incluso algunos procedian de familias judías.

Reinterpretación de la historia: La reinterpretación de la historia era un hecho esperable tras setenta años de deformación ideológica. Se manifiesta en la reivindicación de la sociedad prerrevolucionaria, con la fundación de asociaciones como Nevskii dukhovnyi vestnik (Mensajero espiritual de Nevski) en la actual San Petersburgo. Por otro lado, tenemos el retorno del eslavismo ruso: la idea de que Rusia tenía un modo de vida propio - la aplicación del viejo concepto del volkgeist-. La ampliación del término a las demás repúblicas eslavas, el también añejo paneslavismo, ha dado como resultado el Fon slavianskoi pis'mennosti i slavianskikh kul'tur (Fondo para el recuerdo y la cultura eslava), fundado en marzo de 1989, que trata de fomentar las relaciones entre Rusia, Bielorrusia y Ucrania.

29 "Le problème de l'identité russe est d'une effroyable complexité, car il y a autant d'identités que de citoyens. Il y a déjà une définition négative: la Russie est la grande victime, le pays qui a payé un prix épouvantable à l'Union Soviètique...", Le monde des débats (enero 1993).

36 A. BERELOVITCH: "Le nationalisme russe" en "L'avenir de la Russie", Politique étrangére, $1 / 1992$, p. 39. 
En el sector académico destaca el medievalista D.S. Likhachev. Likhachev forma parte de los moderados, y es precisamente ésta la causa del poco impacto de la Fundación de la Cultura Soviética que dirige. Como se ha dicho anteriormente, comenzó a publicar Nashe nasledie (Nuestra herencia) en septiembre de 1988 y ha rehabilitado a pensadores como el filósofo religioso Florinski. Su mayor proyecto se ha centrado en la Enciclopedia de Rusia.

El impacto de la glasnost en los estudios históricos ha sido fundamental. Se ha ocupado de lleno en las críticas a Stalin, a las colectivizaciones..., se ha glorificado a la NEP, en algunos casos también a Bujarin..., según se sea más o menos liberal, se ha recurrido al siglo XVIII (la apertura al exterior de Pedro el Grande) o al XIX (mitificando al gobierno autocrático).

Propuestas políticas: autoritarismo: La confianza en la solución autoritaria no puede atribuirse solamente a los nacionalistas radicales, pues grandes sectores de la población la han contemplado como única salida viable a la situación planteada. Los llamamientos a la unión nacional apelando al sentimiento patriótico han sido argumentos comunes a todos los personajes públicos ${ }^{31}$. En el mismo sentido iba el "Llamamiento al pueblo", manifiesto patriótico que influyó en los golpistas en agosto de 1991. Entre otros firmantes, se encontraba Boris Gromov, excomandante en jefe de las tropas soviéticas en Afganistán, quien fue viceministro de Defensa, segundo responsable de la Infantería y uno de los hombres señalados por las Fuerzas Armadas para sustituir a Pavel Grachov, el ministro de Defensa, conocido en los círculos militares como «el traidor».

En los últimos años los nacionalistas han incluido en sus manifiestos preocupaciones ecológicas con claras intenciones oportunistas, aunque también son muestra de una auténtica preocupación por los escapes radiactivos tan frecuentes en un complejo energético incapaz de regenerarse o de desmantelarse. Ya en 1986 la oposición nacionalista, junto a otros colectivos, se enfrentó a las pretensiones estatales de llevar a cabo un plan de irrigación que consistía en la desviación de aguas de algunos rios del sur de Siberia hacia Ucrania, Moldavia y especialmente Kazajstán y todo el Asia central.

Retorno a la Iglesia: Éste ha sido uno de los resultados de la perestroika que más se ha hecho notar en los últimos años, e incluso se ha

31 Desde el radical I. ChafAREVITCH "Rusia frente a ella misma" en Pravda, 2-XII-1991 a otros autores como el anónimo redactor de "Por una política de unión nacional y renacimiento de Rusia" en Literaturnaya Rossya, 29-XII-1989. 
hablado de un replanteamiento de las relaciones entre la Iglesia Ortodoxa y el Estado, (de hecho Gorbachov trató de hacer ver a los patriotas que era posible la convivencia). La vuelta a la Iglesia ha sido más frecuente entre la población joven, que ante la falta de otros asideros ideológicos y materiales cree haber quedado sin un marco de referencias al que acudir. El retorno a la Iglesia ha mostrado también el deseo social de renovación moral, que no tiene que ser necesariamente religioso, pero así se manifestará hasta que no existan alternativas éticas coherentes. En esta línea se pronunció I. Romanov en 1988 cuando era director del Centro de Ateismo Científico. En junio de 1988 se celebró el primer milenio de la Iglesia Ortodoxa, con apelaciones a la Gran Rusia y a los símbolos tradicionales. Tales actos se han celebrado posteriormente hasta el punto de que un conjunto de intelectuales publicaron en Nezavisimaya Gazeta (3-IX-1991) una declaración titulada "Iniciativa cívica independiente", en la que advertian de las manifestaciones en favor de una Gran Rusia con la ortodoxa como religión de estado y con la utilización de los símbolos zaristas. Pronto fueron respondidos muy duramente desde Novy mir ${ }^{32}$. Pese a todo la Iglesia Ortodoxa se ha visto obligada a moderar su intransigencia, ya que ante la crisis demográfica de Rusia ha tenido que hacer concesiones a otras religiones, sobre todo al Islam.

Dentro de las clasificaciones que han realizado del nacionalismo ruso en estos años destacan por su difusión las de John Dunlop y Darrell Hammer.

Dunlop ha elaborado un esquema básico que tiene como punto de referencia a Gorbachov:

- Izquierda: Asesores de Gorbachov-nacional liberales-centristas.

- Derecha: Pamiat-nacional bolcheviques-neoestalinistas-conservadores.

Junto al apoyo a las reformas de Gorbachov, Dunlop ha considerado también la actitud que los distintos grupos políticos tienen hacia occidente. Podríamos resumir los planteamientos de Dunlop de la siguiente forma ${ }^{33}$ :

- Nacionalistas liberales: afirma Dunlop que este grupo está formado por intelectuales nacionalistas con los que ha trabajado Gorbachov tratando de evitar la formación de un fuerte movimiento nacionalista opuesto a las reformas. Entre ellos está el ya citado D. Likhachov,

32 Los firmantes de la declaración de la «Iniciativa civica independiente» fueron Afanasev,

Batkin, Bibler, Bonner (la esposa de fallecido Sajarov), Bourtine, Ivanov y Timonfeev.

33 John DUNLOP, The faces of contemporary Russian nationalism, Princeton University Press, Princeton, 1983. 
presidente de la Fundación de la Cultura Soviética, el escritor S. Zalygin, quien desde Novy mir (Nuevo mundo) ha publicado algunas obras de A. Solzhenitsyn, el director de cine E. Klimov etc.

- Centristas: éste es un grupo bastante diverso que rechaza el marxismo-leninismo pero que no se ha mostrado especialmente hostil hacia Gorbachov -aunque no ha aceptado a los miembros no rusos de su equipo: Shatvov, A. Ribakov, G. Baklanov, A. Aganbegyan y $O$. Latsis. Dunlop establece relaciones entre este grupo (en el que ha habido personajes de gran carisma) con Pamiat, aunque podemos considerar que los miembros de Pamiat han resultado ser más radicales en sus manifestaciones (de hecho, entre los llamados centristas había personas que ya en 1988 habian abandonado Pamiat por la radicalización de la asociación, tal es el caso de llya Glazonov). En este grupo destacan V. Astafev, V. Belov, Rasputin, V. Soloukhin, V. Kozhinov, etc-.

- Nacional-bolcheviques: nacional-bolcheviques y neo-estalinistas son dos grupos muy relacionados. Estaban contra los valores occidentales y dadas sus conexiones con el ejército, se ha pensado en ellos como un peligro potencial de dictadura. Algunos han tenido una clara influencia social, como Anatoly Ivanov, que fue director de Molodaya Guardia (Joven guardia), el periódico del Konsomol. Sus posturas se han visto reflejadas en la carta de Nina Andreeva (neoestalinista) a Sovietskaya Rossiya (Rusia soviética) (13-III-1988), que era un manifiesto al parecer inspirado por Ligachov, contra la perestroika, atacando a Gorbachov, a sus seguidores y a los tradicionalistas, quienes, según Andreeva, "hacen comprender el significado histórico de la revolución de 1917». En este grupo sitúa también Dunlop a Yuri Bondarev, P. Proskurin, M. Alekseev (que fue editor de Moskva), etc.

D. Hammer clasificó las fuerzas políticas de la época de Gorbachov en tres grupos:

-- Liberales izquierdistas, favorables a Gorbachov.

- Conservadores y neo-estalinistas (Ligachov).

- Nacionalistas rusos.

Para Hammer, Gorbachov se ha visto obligado a mantener contactos con los nacionalistas y con la Iglesia (con ésta última los contactos no sólo tuvieron carácter político, sino también social, dentro de las campañas para combatir el alcoholismo y la corrupción), aunque también ha señalado que no pudo excederse en las relaciones para no enfrentarse a las 
nacionalidades no rusas minoritarias. Según este mismo autor, los nacionalistas comunistas han remozado su pensamiento según planteamientos paneslavistas y estatalistas, con planes centralizadores. Otro tipo son neoeslavófilos como Solzhenitsyn. En cuanto a Pamiat, según Hammer sólo ha representado una temporal aberración de radicales.

Las valoraciones más interesantes sobre el papel político de los nacionalistas rusos son las que hacen los propios intelectuales rusos. Entre ellas destacan, por ejemplo, las de Andrei Simpavsky, quien ha destacado que el tradicional mesianismo de la «idea rusa» puede tener cierta articulación política si se une al nacionalismo estalinista de carácter imperialista. Considera que hay que tomar muy en serio a Pamiat por sus mensajes agresivos. Sin embargo, R. Suny (nacionalista) ha quitado importancia al neoestalinismo, pues las revelaciones de los crímenes cometidos en el periodo parecen haber desprestigiado estas posiciones.

El antiguo disidente Alexandr Yanov ya avisó, antes de la llegada de Gorbachov, del peligro fascista que implicaban los comportamientos nacionalistas. Recordaba Yanov las pretensiones de expansionismo que podían detectarse en algunos militares y nacionalistas, que respondian a la vieja ideología del Derecho Ruso (ideología que en el siglo xix justificó el imperialismo zarista por Asia). En definitiva, Yanov parecía especialmente preocupado por la potencial influencia de los nacionalistas en las masas, dado su carácter demagógico y la capacidad periodística que poseen, habiendo conseguido atraer a artistas, escritores...

Para A. Tsipko, es inconcebible hablar de un Estado ruso monoétnico, ya que se pueden encontrar al menos tres identidades nacionales rusas: una antigua idea nacional asociada a la historia, una identidad plurinacional que corresponde a la RSFSR y una última entidad siberiana. Destaca por tanto, la búsqueda de la esencia rusa en función de una pretendida raza o de la lengua y afirma que en estos movimientos nacionalistas confluyen una idea imperial, una conciencia de poder: rossiiskoe, la idea de la conciencia nacional rusa en términos étnicos: russkoe. Para los occidentales puede resultar un tanto confusa esta distinción, ya que nosotros traducimos ambos términos por una misma palabra: ruso.

En los años que nos ocupan, Alexandr Solzhenitsyn, el disidente más ilustre, fue la imagen más clara de un nacionalista en busca de la esencia rusa. Rechazaba basarse en la civilización occidental para rehacer Rusia, ya que occidente también estaba en crisis. Propuso un programa de renovación basado en el eslavismo según esquemas que ya se hallaban presentes en escritores como Dostoievsky. Reclamaba un politica de paz y un desarrollo moral personal y colectivo. Opinaba que Rusia no estaba 
preparada para la democracia y que un sistema multipartidista no provocaría más que inestabilidad. En este sentido iba la carta enviada al embajador ruso en Washington, $V$. Lukin, manifestando un claro apoyo a Yeltsin: "La Federación rusa, enorme y variopinta no puede sobrevivir sin un poder presidencial fuerte, que en ningún caso puede ser menor que el existente en Estados Unidos" ${ }^{34}$. En suma, Solzhenitsyn ha de ser contemplado como un nacionalista liberal que busca la regeneración de los rusos a través de la ortodoxia.

\section{EL NACIONALISMO RUSO ANTE LA PERESTROIKA}

El problema de la construcción de un estado en Rusia se encuentra directamente conectado con la definición de la ciudadania rusa ${ }^{35}$ que es, en última instancia, la formación de una identidad nueva. El movimiento constante de la política rusa ha hecho que la reivindicación de la autonomía de las repúblicas de la RSFSR haya pasado en los años ochenta de manos de la "Rusia democrática" de Yeltsin a la oposición.

El impacto de la glasnost en el panorama político fue muy importante: la retransmisión televisiva de las sesiones del Congreso de los Diputados del Pueblo en 1989 se convirtió en un hito. Para los nacionalistas, la glasnost dio paso a la salida de la semiclandestinidad que se plasmó en la publicación de periódicos de carácter conservador como Nash Sovremennik (que podríamos situar en el centro), Moskva (en la derecha) ${ }^{36} \mathrm{o}$ en el "rejuvenecimiento" de Molodaya Guardia, publicado por el Konsomol. Por otra parte las asociaciones más o menos nacionalistas parecian aflorar por doquier: Pamiat (Memoria), Fon slavianski pis'mennosti i slavianskikh kul'tur (marzo de 1989), Tovarishchestvo russkikh khudozhnikov (noviembre de 1989; Asociación de Artistas rusos, coordinada por Rasputin, Belov, Ivanov y Vikulov, cuya principal actividad se centra en combatir a las minorías separatistas), Nevskii dukhovnyi vestnik (Mensajero espiritual de Nevski), etc. La celebración del milenario de la Iglesia Ortodoxa (1988) aparecía como la culminación de un periodo de prohibiciones.

\footnotetext{
El Pais, 9-111-1993.

K. ROUSSELET, "En guise d'introduction: nation, État et démocratie en Russie", en "L'avenir de la Russie", Politique étrangére, 1/1992, p. 19. Sobre esta cuestión puede resultar interesante la lectura del libro de M. Mendras (dir.), Un État pour la Russie, Bruselas, Complexe, 1992.

36 Ambas publicaciones están asociadas a la prestigiosa Unión de Escritores de la República
} Rusa. 
La actuación de los nacionalistas radicales en los inicios de la perestroika consistió básicamente en una serie de tanteos al poder, tratando de dilucidar hasta qué punto las autoridades iban a consentir sus provocaciones. En estos primeros años que van de 1985 a 1989, los nacionalistas aún no tenían un suficiente apoyo social, por lo que sus actividades públicas estaban también encaminadas a hacerse notar entre la población rusa, insistiendo en viejas heridas y aprovechando el agravamiento de la situación económica con planteamientos demagógicos que nada tenían que ver con la auténtica realidad de la crisis: el estancamiento del sistema de planificación imperativa y el impacto brutal de las nuevas indicaciones económicas de los reformistas. El hecho que podría resultar más esclarecedor fue la manifestación celebrada en Moscú en 1987, a la que acudieron los nacionalistas más radicales, quienes lograron presionar hasta obtener un audiencia de Yeltsin (primer secretario del PCUS en Moscú). Este acontecimiento fue observado desde muy distintos puntos de vista, de forma que para algunos constituyó un elemento fundamental en la vida política rusa, mientras que para otros no fue más que una algarada de extremistas que no debía ser tomada en consideración. Sea cual sea el impacto de acontecimientos como éste, lo que no podemos olvidar es el hecho de que en las elecciones de 1989 no obtuvieron un gran éxito, por lo que es posible afirmar que en los años de Gorbachov, los nacionalistas radicales se dedicaron fundamentalmente a definir y modificar sus posiciones en función de las circunstancias. El agravamiento de la situación económica y la nueva posición de Rusia en el panorama internacional pudieron ser las causas del relanzamiento de estos grupos extremistas, causas que, desde luego, constituían elementos exteriores al movimiento nacionalista. Pese a todo, los llamados "patriotas" han tratado de llevar a cabo desde finales de 1989 un proceso de reorganización. Una de sus manifestaciones públicas más destacadas fue la carta enviada a Gorbachov que apareció en Sovietskaya Rossiya el 22 de diciembre de 1990 con el título "Con fe y esperanza». El manifiesto estaba suscrito por miembros de Ejército, del Partido, escritores nacionalistas y otros radicales (Belov, Projanov, Bondarev) y representantes del complejo militar-industrial. El patriarca Alexis II retiró su firma posteriormente. Las ideas presentadas en este artículo no contenían nada novedoso: "El valor supremo que nos ha legado una historia milenaria, nuestra Patria, está amenazada... por una dictadura funesta de personas... con voluntad de tomar posesión del territorio, de los recursos...". Son los mismos planteamientos que se escucharon en Rusia los dias previos al golpe de agosto de 1991, e incluso meses antes, en el programa que el Movimiento Social-Patriótico de Rusia presentó para las elecciones del Parlamento ruso en marzo de 1990: "Por una política de unión nacional y el renacimiento de Rusia». 
En definitiva, pese a la denuncia de que fueron objeto Ligachov y Chebrikov en el Pleno del Comité Central del PCUS en septiembre de 1988, Ligachov continuaba siendo el centro de la oposición conservadora a la perestroika hasta el golpe de 1991. De esta forma, el nacionalismo se constituía (muy difusamente) en la tercera fuerza política de Rusia detrás de los reformistas y de los llamados nacionalistas liberales (que eran también una amalgama muy diversa de personajes: desde eslavófilos moderados a socialdemócratas). Fue la facción de Ligachov en el Politburó en 1989 la que estableció las referencias que los nacionalistas podian contemplar para una posible alianza que se ha desarrollado en el periodo de gobierno de Yeltsin. A pesar de todo, esta unión con los neoestalinistas no estaba, en principio, muy destinada al éxito, ya que continuamente se sacaban a la luz (actualmente se mantiene esta revisión) más pruebas acerca de los crímenes de Stalin, lo que evidentemente, no conducía más que al desprestigio de los nostálgicos del dictador georgiano. Las líneas que definieron la actuación de los nacional-bolcheviques y neoestalinistas no es compartida por todos los autores; en realidad, no resulta posible marcar distinciones claras, ya que éstas dependen de las circunstancias y sobre todo, de los personajes que en un determinado momento pudieran ser considerados lideres de la facción. No es cuestión de programas, sino de oportunismo político, cuya prueba más evidente es el pacto entre el conservador Ligachov y la estalinista Nina Andreeva, unión en la que el nacionalismo formaba parte de la habitual demagogia del discurso político.

Carter propuso un esquema circular para la compresión de la política rusa a finales de los ochenta que representa, aparte de un loable intento, una herramienta bastante útil, pero que queda un tanto desfasada en los noventa ante el ritmo vertiginoso de la misma ${ }^{37}$. El giro a la derecha ha sido general en nuestra década, aunque hablar de derecha e izquierda en la actual Rusia requiera olvidar algunos esquemas previos.

Por tanto, las conexiones que mantuvo Gorbachov con los nacionalistas y la Iglesia pueden ser calificadas de tácticas, ya que la alianza natural (en los términos de avance hacia el progreso y la democracia planteados por Gorbachov) se estableció con los occidentales (quienes, al fin y al cabo, eran los que podían aportar las inversiones para el desarrollo económico) y con los demócratas rusos, los que contribuían a la estabilidad política.

Hemos dejado para el último lugar el análisis de Pamiat, por ser un ejemplo muy ilustrativo de la evolución de los nacionalistas en Rusia y por

37 S.K. Carter, Russian Nationalism. Yesterday, Today, Tomorrow, Pinter Publishers, Londres, 1990. 
representar, en su momento, el colectivo con más fuerza y posibilidades de acción. Pamiat (Memoria) y Otechestvo (Patria) nacieron en los ochenta como ejemplos del nuevo nacionalismo defensivo y extremista, que bajo la máscara de la cultura, tenian unas claras intenciones políticas que no se le escapaban a ningún observador. Comenzó a ser conocida como una sociedad que daba conferencias culturales (historia y literatura rusas) en el Ministerio de Aviación a principios de la década de los ochenta. Se desarrolló en clubes de Moscú, como el Rodina, y de Leningrado, como el Rossiya, aunque ya en 1988 Leninskadskaya Pravda publicaba que el grupo tenía ramificaciones en treinta ciudades de la URSS.

Desde 1985 Pamiat comenzó a desarrollar claros matices antisemitas y racistas en general en sus discursos y conferencias, alcanzando tonos neofascistas en varias ocasiones. Se detectaron contactos entre Pamiat y algunos miembros del Partido: las conferencias en el ministerio de Aviación son un evidente ejemplo, así como el hecho de que Kim Andreev, presidente de la sociedad, fuera propuesto como candidato para el Soviet local en 1985-86. Así mismo, en Novosibirsk han utilizado la Casa de la Cultura de la Academia de Ciencias de Siberia.

La estrategia de Pamiat ha sido tratar de ampliar su ámbito de influencia a través de sociedades hermanas como Otechestvo en Sverdlosk, o mediante la absorción de asociaciones ya existentes como la VOOPIK en 1987 (la Asociación Rusa para la Preservación de los Monumentos Históricos y Culturales). El 6 de mayo de 1987 esta asociación convocó una concentración en la que estuvo el entonces primer secretario del PCUS en Moscú, que no era otro que Boris Yeltsin. En aquella manifestación se lanzaron duras acusaciones contra la perestroika y Gorbachov. Este hecho supuso el reconocimiento casi oficial, al menos por tal fue tomado, de la Asociación. Durante 1989 los miembros de Pamiat se dedicaron a reventar la campaña electoral de los reformistas para la elección del nuevo Consejo de los Diputados del Pueblo.

En diciembre de 1987, Pamiat publicó un manifiesto que recogía lo fundamental de su ideología y que iba dirigido "al pueblo ruso, a los patriotas de todos los países y naciones" (la misma fórmula utilizada por la Iglesia y por Stalin en distintas ocasiones). Sus planteamientos, que consistían sobre todo en críticas, pueden resumirse en tres puntos: críticas a la situación del pais, a la historia pasada, la soviética, y a la perestroika. La idea que difundió $\mathrm{Pa}$ miat sobre la situación del país sólo contribuyó a enturbiar el panorama político y a desvirtuar la esencia de las reformas, pues si rechazaban las nuevas propuestas también criticaban el antiguo sistema de planificación, siendo su alternativa una vuelta a la sociedad tradicional campesina. 
La imagen del enemigo de la nación rusa tampoco ha estado ausente: eran, una vez más, el masón y el judío, a los que se unía el occidental. Vasiliev, fotógrafo nacionalista vinculado a Pamiat, unió los Protocolos de los Ancianos de Sión a la Sociedad. En definitiva, podemos detectar en el manifiesto los siguientes temas:

- Demandas de mejoras para el pueblo (entre ellas se proponía que Pamiat pudiera disponer del control de los medios de comunicación).

- Demandas de libertad religiosa (la mayoria eran ortodoxos, aunque predominaba la ambigüedad y el oportunismo en este aspecto, pues a veces, las posturas en cuestión religiosa no aparecian claramente definidas).

- Utilización de un idioma ruso puro.

- Críticas a los setenta años de terror ${ }^{38}$.

- Existencia de enemigos del país: los judíos, masones, occidentales, los líderes del poder soviético que han destruido la nacionalidad rusa y el "reactivado trotskismo".

Frente a este conjunto de lugares comunes, destacaba la siguiente petición: "Pedimos la convocatoria de un Tribunal del Pueblo para la investigación de las actividades de todos los usurpadores del poder... ¡Ya ha habido suficientes faltas!. Su resultado ha sido un montón de vidas humanas, mares y ríos de sangre!...". Políticamente, acentuaban las alabanzas al zarismo y sobre todo al zar Nicolás II, apostando por una solución autoritaria y afirmando que la "verdadera situación puede ser calificada con una sola frase: hemos democratizado un poco y esto ha sido suficiente".

Pamiat tenia unos cuantos "objetivos personales" que han sido el centro de sus críticas, y que iban desde el editor de Ogonyok Vitalii Korotich, a la socióloga Tatiana Zalavskaya (por sus orígenes judíos; también estaba fichada por la KGB), aunque las iras más furibundas fueron a para a Abel Aganbegyan (acusado de ser el ideólogo de la perestroika) y a Alexander Yakovlev (acusado de rusófobo).

La sociedad tenía importantes apoyos en el Ejército y en intelectuales como Rasputin, Kozhinov, Bondarev etc. y ha publicado en periódicos

38. Pamiat ha personificado sus críticas al periodo estalinista en Kaganovich (uno de los miembros del Politburó más cercano a Stalin). Incluso se llegó a pedir su ahorcamiento. Para su desgracia, Kaganovich era de los pocos que vivian aún al comienzo de la glasnost (Molotov había muerto en 1986), y esto, junto a su condición de judio, le convirtió en centro de todas las iras, pues a Molotov y a Zhdanov al menos se les consideraba patriotas, y Stalin, al fin y al cabo, habia transformado a Rusia en una primera potencia mundial. 
como Molodaya Guardia, Moskva y Nash Sovremennik. Las reacciones del régimen soviético hacia Pamiat fueron muy diversas, pues si por una parte se rechazaron sus ataques, por otro, los elementos más conservadores, opuestos a las reformas, veían en la asociación un instrumento para lanzar a la sociedad contra la perestroika. Un buen ejemplo de esta situación eran los miembros del Comité Regional del Partido en Leningrado, quienes durante 1988 iban con frecuencia a las conferencias de $\mathrm{Pa}$ miat en los jardines de Rumiantsev.

Los reformistas propusieron la persecución judicial de Pamiat basándose en el artículo 74 del Código Criminal de la RSFSR por "violación de los derechos de las nacionalidades y las razas" y por apoyar a movimientos neofascistas y nazis, pero no ha podido lograrse la prohibición, entre otras cosas, por los grandes apoyos de que gozaba la asociación en el seno de las estructuras del Estado.

La llegada de Boris Yeltsin al poder supuso un giro a la derecha de toda la política rusa. Yeltsin, antiguo crítico de la situación económica del país, se vio obligado a recurrir a argumentos bastante peculiares para justificar sus actuaciones. Una de las tácticas empleadas fue el fomento del nacionalismo (que poco a poco ha ido dejando de ser monopolio de los radicales). Esta estrategia presentaba bastantes riesgos, sobre todo en cuestiones como las relaciones con las antiguas repúblicas de la URSS: la petición de que la ONU debe encargar a Rusia la seguridad de la zona de la ex URSS, fue contestada casi ferozmente por Ucrania. Junto a esto, Yeltsin advertía de la posible aparición de los uherederos de la ideología comunista, el nacionalismo y el fascismo en sus peores manifestaciones" ${ }^{39}$. Pese a todo, a Yeltsin no parece haberle quedado más remedio que hacer concesiones a los conservadores: en su momento, el nombramiento de Chernomirdin como primer ministro fue la mejor prueba, lo que provocó la dimisión de Gaidar ( la «bestia negra» de los nacionalistas). De hecho, quien fuera ministro de Asuntos Exteriores, Kozirev, uno de los pocos reformistas que aún quedaban cerca de Yeltsin, pronunciaba un discurso en la reunión de la CSCE en diciembre de 1992 que el en el fondo era un llamamiento a occidente para tratar de frenar la liquidación de las reformas ${ }^{40}$.

Desde principios de los noventa y sobre todo tras el golpe de 1991, los nacionalistas parecen haber adoptado una nueva táctica que les ha

9 El Pais, 29-XI-1993.

40 The Independent, 15-XII-1992. 
permitido presentar a Yeltsin como el culpable de la desagregación de la URSS. En esencia, la nueva estrategia consistió en dar su apoyo a los nacionalistas de otras repúblicas, a la vez que criticaban los movimientos separatistas de las repúblicas no rusas de la RSFSR. Junto a esto, han intervenido en las actividades de los rusos que viven en otras naciones: apoyo a la población rusa del Kazajstán, a la creación del Interfront, organización de los rusos de Letonia que trata de impedir que sus hijos aprendan obligatoriamente letón en las escuelas... Destaca en este sentido la iniciativa tomada en septiembre de 1989 en el Congreso del Frente Unido de Trabajadores Rusos celebrado en Sverdolsk, en el que se abogó por los rusos residentes en otras repúblicas de la ex URSS.

Las críticas más feroces a la situación procedían del relativamente nuevo Frente de Salvación Nacional (FSN), alianza de comunistas del PCR (Partido Comunista de Rusia) y nacionalistas. Alexandr Projanov, del FSN, sintetizó sus críticas a Yeltsin en unas declaraciones a periodistas extranjeros, basándose en la hipoteca de la política exterior de Rusia a los intereses de occidente, y en la crítica situación económica ${ }^{41}$. Projanov ha definido los caracteres de la alianza entre nacionalistas y comunistas al afirmar que el PC "se había nacionalizado", es decir, que sus objetivos están en el mantenimiento de las estructuras del Estado frente al actual proceso de desarticulación ${ }^{42}$. La descripción de la situación interna del país se elaboraba a partir de las críticas a los comunistas dogmáticos que ahora figuraban, según Projanov, entre los demócratas: "La gente que hacía del PCUS un partido dogmático, leninista, se pasó al bando de los demócratas. Todos los teóricos que daban al Partido un tono marxista - Yakovlev, Popov, Afanasiev, Burbulis-, cambiaron de filosofía, dejando al PCR prácticamente sin ideólogos". El líder de este renovado PCR es Guennadi Ziuganov, "ajeno a los dogmas marxistas-leninistas". En cuanto al apoyo de los militares. Projanov daba a entender que el FSN era capaz de movilizarlos en cualquier momento, aunque ahora prefirieran actuar por vía parlamentaria. En definitiva, Projanov insistía en la capacidad de arrastre del FSN , cuya posición política calificaba como centro-izquierda. Esto nos dice mucho acerca, primero, de las intenciones del FSN de tratar de reducir su imagen extremista, y segundo, de cómo estaba configurado el espectro político ruso, en el que no tienen lugar, como ya se ha dicho anteriormente, nuestros esquemas políticos occidentales. Otro lugar común en el discurso de Projanov aparecía en estas declaraciones sobre

\footnotetext{
El Pais, 20-1II-1993.

Los componentes de esta alianza eran conocidos como los rojipardos. Unos de sus principales medios de expresión es el semanario Deñ (El Día), de A. Projanov.
} 
la deslegitimación de Yeltsin, "Yeltsin encabeza un régimen de ocupación» afirmaba Projanov, tratando de desestabilizar el sistema, de ahí que fuera fácil explicarse sus actuaciones en 1991 impulsando a los futuros golpistas a movilizarse.

El Tribunal Constitucional de Rusia dio en noviembre de 1992 un dictamen por el que se permitia la existencia de partidos de carácter comunista, pero prohibía restaurar las estructuras del PCUS y del PCR, abolidos por Yeltsin tras el golpe de 1991. Evidentemente, ambas formaciones se desarrollaron en la ilegalidad. La división entre los llamados duros y los socialdemócratas ha sido clara desde el principio. El sector socialdemócrata ha estado representado por el Partido Socialista de los Trabajadores (dirigido por Roy Medvedev, quien consiguió el registro oficial de su formación), y Valentín Kupzov (dirigió el PCR antes del golpe, y después abogó por una vía democrática y centralista que conjugara socialismo y mercado). Los sectores duros, susceptibles de alianza con los nacionalistas, estaban representados por el Partido Comunista de los Trabajadores de Rusia (RKRP, dirigido por Viktor Tiulkin) y el Partido Comunista Soviético, cuya presidenta era Nina Andreeva. En febrero de 1993, los herederos del PCUS celebraron un congreso para tratar de reorganizarse y planificar sus actuaciones, pero dada la diversidad de opiniones y de posturas, resultó difícil llegar a un acuerdo. En este congreso estuvieron también los golpistas de agosto de 1991, muy aplaudidos por los comunistas alli presentes.

Desde la disolución de la URSS, uno de los principales asuntos que movilizaron a los nacionalistas era la supuesta hipoteca de las relaciones exteriores de Rusia en cuestiones como la reducción de armamento nuclear (START II), la guerra de Yugoslavia y la cumbre de Vancouver.

La reducción de armamento era un aspecto especialmente peliagudo porque ponía en relación las críticas de los nacionalistas con las de los militares, entre los que el malestar ha llevado a manifestaciones de nostálgicos soviéticos en la Plaza Roja, en las que se calificaba a Bush de asesino y a Yeltsin de traidor ${ }^{43}$. Las reacciones frente al START II ya comenzaron cuando el 17 de junio de 1992 Bush y Yeltsin firmaron en Washington una "Carta de Cooperación y Amistad» y una declaración de intenciones para concertar el tratado. Ante las críticas suscitadas, Boris Yeltsin no ha parado de tranquilizar al país, y en especial a los militares, acerca de la seguridad de Rusia.

4:3 Le Monde, 4-I-1993. 
La guerra de Yugoslavia colocó a los dirigentes rusos en una situación bastante incómoda, pues si por un lado se veían obligados a seguir la línea occidental, por otro estaban presionados por su tradicional alianza con Serbia. Los nacionalistas hicieron de esta cuestión un asunto propio, y abogaron por el apoyo a Serbia como nación eslava y ortodoxa. Yeltsin, consciente de esto, logró posponer las sanciones del Consejo de Seguridad de la ONU contra Serbia con vistas al referéndum del 25 de abril. Lo mismo cabe decir de la cumbre de Vancouver en abril de 1993: Ios nacionalistas acusaron a Yeltsin de ir a mendigar a EEUU.

En todo este complejo escenario político, los militares han sido el punto de mira de todo el mundo, especialmente de los nacionalistas, quienes buscaron en ellos el asidero que les faltaba para dotar a sus amenazas de un elemento que les diera auténtico valor. Ciertamente, dentro del Ejército ha habido militares demócratas, agrupados en la organización denominada Shchit (Escudo), pero, debido a disputas internas, perdieron su influencia. La Unión de Oficiales, por otra parte, ha sido el grupo conservador y nostálgico del antiguo poder de la URSS. Para algunos observadores representó el brazo armado del FSN, y pudo ser considerado un peligro de dictadura fascista, según declaró E. Kozhokin, vicepresidente del Comité Parlamentario de Defensa y Seguridad ${ }^{44}$. La Unión de Oficiales estuvo dirigida por el teniente coronel Stanislav Terejov, quien presidió el 20 de marzo de 1993 una asamblea - prohibida- de oficiales (en locales del Parlamento ruso) en la que, entre otras cosas, se pidió la dimisión de Grachov, el ministro de Defensa. Han existido también otras organizaciones como los Combatientes del Frente Invisible, grupo clandestino creado entre los militares destinados en el Báltico, de quienes también se temieron conspiraciones.

\section{CONCLUSIÓN}

El estudio dei nacionalismo ruso presenta problemas muy complejos relacionados con la variedad de manifestaciones que ha adoptado a lo largo de la historia. El problema fundamental, y tal vez el más interesante, es dilucidar su grado de conexión, y a la vez de contradicción, con el Estado comunista, ya que éste ha sido capaz de cumplir la tan ansiada misión de Rusia en la historia del mundo, aspecto éste de primordial importancia para el pensamiento mesiánico tradicional. La relación entre

${ }^{44}$ El Pais, 22-III-1993. 
comunismo y nacionalismo ha sido la de una síntesis en las intenciones y una antitesis en los principios ideológicos de partida, que ha dado lugar a una absorción teórica por ambas partes, cuyos frutos han sido los movimientos neo-estalinistas y conservadores como Pamiat o el Frente de Salvación Nacional.

El nacionalismo ruso se presenta en nuestra época como la manifestación política de un sentimiento de frustración, de una profunda crisis en la definición de la identidad nacional de un pueblo, el ruso, que estaba profundamente identificado con la "idea soviética" y que, con el hundimiento de ésta, parece haberse caído también la fuerza que lo sustentaba. Al lado y como consecuencia de esta crisis, han surgido en la actualidad elementos demagógicos que recogen por un lado la herencia zarista, y por otro las críticas a la presente situación económica, política y social. Obviamente, en semejante caldo de cultivo, el nacionalismo radical ruso se ha encontrado con una situación ideal para articularse políticamente. Desde el fin de la URSS, el nacionalismo ha dejado de ser patrimonio de los más radicales. En una fecha no tan alejada de los hechos, el historiador Alexandr Tsipko escribia: "Antes de la disolución de la Unión Soviética, de cualquiera que pronunciaba la palabra patriotismo podía pensarse que era de Pamiat, ahora incluso los ideológos del patriotismo de sangre tienen aspecto muy respetable y la gente ha empezado a escucharles. La tesis de que sólo la ideología del nacional ruso puede salvar el Estado, se está haciendo muy usual en la prensa" ${ }^{45}$.

45. "La nueva Rusia: conflictos, contradicciones y esperanzas", en Politica Exterior, vol. VI!, n. 33, p. 18. Aunque escapa al periodo cronológico objeto de nuestro estudio, no es posible dejar te mencionar la tan conocida figura de Zhirinovsky, ejemplo de esos personajes descritos por Tsipko. Al respecto, recomiendo el análisis que sobre él ha realizado recientemente Robert SERVICE: "Zhirinovsky: Ideas in Search of an Audience", en G. Hosking y R. Service (eds.), Russian Nationalism. Past and Present, University of London, Londres 1998, pp. 179-197. 